\title{
Corrupción y ayuntamientos
}

\author{
Marina Mínguez RosiQue \\ Profesora Ayudante Doctora \\ Universidad Autónoma de Madrid
}

Palabras clave: Derecho penal; Administración pública; funcionario público; corrupción; prevaricación; desobediencia; fraude a la Administración.

Keywords: Criminal Law; public administration; civil servant; corruption; administrative prevarication; disobedience; fraud against the Public Administration.

SUMARIO: I. CASOS Y JURISPRUDENCIA RELEVANTE DEL AÑO 2020: 1. Prevaricación: 1.1. La resolución arbitraria y la diferencia con la mera ilegalidad. 1.2. La cooperación y el problema del engaño. 1.3. La necesidad de dolo directo. 1.4. Relaciones concursales. 1.5. El delito de nombramientos ilegales. 2. Desobediencia y denegación de auxilio: 2.1. La relación entre los arts. 410 y 411 CP. 3. Tráfico de influencias. 4. Fraude a la Administración.-II. BIBLIOGRAFÍA.

\section{CASOS Y JURISPRUDENCIA RELEVANTE DEL AÑO 2020}

\section{Prevaricación}

Según inveterada doctrina jurisprudencial del Tribunal Supremo, para poder hablar de prevaricación deben confluir cuatro elementos: i) el dictado de una resolución arbitraria por autoridad o funcionario en asunto administrativo; ii) que se ocasione un resultado materialmente injusto; iii) que la resolución se dicte con la finalidad de hacer efectiva la voluntad particular de la autoridad o funcionario, consciente de que actúa contra el Derecho, y iv) que la actuación sea intencionada, es decir, a sabiendas: que se adopte la resolución "con pleno conocimiento de su injusticia» (por todas, STS 606/2017, de 7 de julio).

Podemos encontrar dos claros ejemplos de prevaricación en la STS 664/2020, de 3 de diciembre, en la que, entre otros extremos, se aborda la actuación del exalcalde 
de Santa Coloma de Gramanet (Barcelona) en el denominado caso Pretoria. En dicha sentencia, el Tribunal Supremo confirmó las dos condenas por prevaricación de dicho sujeto: la primera de ellas, por motivar una nueva adjudicación de terrenos ocultándola al ayuntamiento, sin que los nuevos adjudicatarios tuvieran la cualificación exigida (lo que exigiría una nueva licitación), sin hacerse una nueva valoración de los mismos y con cambio de usos urbanísticos; la segunda de ellas, por conseguir que el Pleno del Ayuntamiento otorgara un contrato de limpieza municipal a sabiendas de que, con su adopción, lograba la imposición de su propia voluntad en beneficio de un concreto particular, con menoscabo de los principios que han de regir la actuación de las Administraciones públicas, es decir, con plena conciencia de su ilegalidad.

\subsection{La resolución arbitraria y la diferencia con la mera ilegalidad}

Para que pueda hablarse de prevaricación, el art. 404 CP exige el dictado de una resolución administrativa, quedando excluidos de la aplicación de dicho precepto todos aquellos actos administrativos que no ostenten carácter decisorio (como, p. ej., los de trámite: informes, consultas, circulares, dictámenes...). La STS 227/2020, de 22 de mayo, recuerda cuáles son las características que deben concurrir en dicha resolución: en primer lugar, debe ser un acto de contenido decisorio que resuelva definitivamente sobre el fondo de un asunto y con eficacia ejecutiva; y, en segundo lugar, es necesario que la autoridad o funcionario público realice un acto que suponga una absoluta incompatibilidad con el ordenamiento jurídico y con los principios que lo inspiran. Así, es necesario que la resolución resulte arbitraria en el sentido de que, además de contrariar la razón, la justicia y las leyes, lo haga desviándose de la normal praxis administrativa de una manera flagrante, notoria y patente, esto es, que el sujeto activo dicte una resolución que no sea el resultado de la aplicación del ordenamiento jurídico, sino, pura y simplemente, una voluntad injustificable revestida de una aparente fuente de normatividad. No habrá, por tanto, prevaricación cuando nos encontremos ante una mera ilegalidad, una interpretación errónea, equivocada o discutible.

Son varias las sentencias del Tribunal Supremo durante el año 2020 en las que se ha discutido el carácter de resolución arbitraria, objeto material del delito de prevaricación. Así, en la ya mencionada STS 227/2020, de 22 de mayo, el Alto Tribunal tuvo que pronunciarse sobre este aspecto en el denominado caso Escalinata. En este caso, el Ayuntamiento de Algeciras había adjudicado a una empresa la construcción y explotación de un aparcamiento, y, tras el inicio de las obras, el edificio bajo el cual se estaba construyendo comenzó a sufrir graves daños como consecuencia de las mismas, razón por la que tuvo que ser desalojado. Meses después, los vecinos de dicho edificio volvieron a ocuparlo, tras haber obtenido un compromiso verbal de que se arreglarían los desperfectos, lo cual no solo no sucedió, sino que, además, el edificio sufrió otro desplome que llevó a su abandono de manera definitiva. El alcalde y el presidente de la comunidad de propietarios firmaron un acuerdo en virtud del cual el ayuntamiento se 
encargaría de que la empresa constructora abonara los daños y los realojos a los vecinos mientras no pudieran ocupar sus viviendas: unas cantidades que fueron adelantadas por el ayuntamiento, que se erigió en garante, y que la empresa constructora finalmente no abonó. Tiempo después, el alcalde, pese a conocer la situación de los vecinos y ser consciente de que los daños del edificio se debían a las obras realizadas por la empresa concesionaria, dictó un decreto mediante el cual exigía a los vecinos que reparasen el edificio. Precisamente por dicho decreto es por el que la Audiencia Provincial de Cádiz condenó al alcalde de esta localidad por un delito de prevaricación. En su recurso ante el Tribunal Supremo, la defensa del alcalde alegó la indebida aplicación de este delito, sosteniendo que el decreto emitido era un acto de mero trámite de iniciación de un procedimiento sin efecto ejecutivo. En este sentido, el Tribunal Supremo estableció que el mencionado decreto no podía considerarse un mero acto de trámite, calificándolo como un acto complejo que iba más allá de una simple incoación del expediente, pues añadía una declaración de voluntad emitida por el alcalde exhortando a la comunidad de propietarios a realizar un acto concreto con advertencia expresa de los efectos de su incumplimiento. Así, la mera apertura de un expediente es un acto de trámite, pero si además de esa decisión se incluyen disposiciones ejecutivas, la decisión adquiere el carácter de resolución administrativa a los efectos previstos en el art. 404 CP. Sin embargo, pese a la concurrencia de este elemento, el Tribunal Supremo consideró que no podía hablarse de prevaricación por no concurrir el requisito de arbitrariedad. En este sentido, sostuvo que la postura del ayuntamiento fue en todo momento de garante, correspondiendo a la comunidad de propietarios la realización de las obras de conservación del edificio, y a la empresa constructora del aparcamiento el pago de los daños ocasionados derivados de los trabajos realizados en la construcción del aparcamiento, así como el resarcimiento de los gastos ocasionados como consecuencia del desalojo del edificio. Así, estimó que el comportamiento del alcalde no entrañaba una «llamativa, grosera, flagrante, clamorosa o esperpéntica injusticia que pueda ser apreciada por un lego por apartarse de cualquier opción jurídicamente defendible»: al no existir una discordancia patente y clara entre la resolución dictada y el ordenamiento jurídico, comprensible por cualquiera por carecer de explicación razonable, estableció que su conducta no era subsumible en el delito de prevaricación.

También en relación con el posible carácter de resolución administrativa de las aperturas de expediente en función de su contenido se pronuncia la STS 409/2020, de 20 de julio, reiterando lo señalado por el pronunciamiento anteriormente mencionado. Así, dicha sentencia estableció que era una resolución administrativa la apertura de un expediente disciplinario en el que se disponía la suspensión de empleo y sueldo de una funcionaria con efecto inmediato desde su notificación.

Por otro lado, el carácter de mera ilegalidad fue señalado, por ejemplo, en el ATS de 6 de octubre de 2020, en el que se dirimía el caso del alcalde de Girona, quien había adquirido para el Museo Municipal una colección de obras de arte habiendo abonado parte del precio (1.000.000 de euros) con el importe recibido por el ayuntamiento en una operación de prórroga de concesión para gestionar el cobro del canon del agua, y 
cuyo destino debía haber sido la financiación del gasto municipal relacionado con el ciclo integral del agua. Señala en esta ocasión el Alto Tribunal que se trata de una ilegalidad administrativa, pues se utilizó el canon del agua sin respetar sus límites finalísticos y presupuestarios, pero que no puede entenderse que la resolución dictada lo fuera por un órgano incompetente, ni que se hubiera prescindido de las normas esenciales de procedimiento, ni que fuera consecuencia de la comisión de una infracción penal o expresión de la misma. Así, reiteró que la desviación de finalidad pública constituye únicamente un ilícito administrativo.

\subsection{La cooperación y el problema del engaño}

La STS 696/2019, de 19 de mayo de 2020, confirma la condena por prevaricación del exalcalde de Jerez de la Frontera (Cádiz), que también había sido presidente y posteriormente vicepresidente de la Gerencia Municipal de Urbanismo. En este caso, tanto él como el gerente de la Gerencia Municipal de Urbanismo idearon un procedimiento de permuta de unos terrenos municipales para evitar una venta pública, incurriendo en graves defectos y omisiones en la tramitación del procedimiento. Así, con la intención de beneficiar a una determinada empresa, adquirieron, a cambio de dicho terreno, un inmueble que no fue destinado a ningún uso o servicio, encontrándose en estado de semirruina. Debe señalarse, además, que el exalcalde no disponía de facultades para transmitir la totalidad de la finca; hecho pese al cual llevó a cabo la permuta sin que el gerente realizara comprobación alguna. En dicha sentencia también se confirma la condena como cooperador necesario de un delito de prevaricación a dicho gerente, pues, según expone el pronunciamiento, en la arbitraria elección del tipo de procedimiento y en la tramitación que llevó a la resolución injusta, su intervención fue imprescindible, tanto por el inadecuado ejercicio de sus funciones, como por la decisión consciente, dolosa y deliberada de consentir la violación de las normas de contratación aplicables en lo que se actuó bajo su supervisión, que permiten un el juicio de equivalencia entre la acción y la omisión que exige el art. $11 \mathrm{CP}$. Así, pese a no haber firmado el convenio de permuta, su aportación imprescindible es equiparada a la autoría en virtud del art. $28 \mathrm{CP}$.

Por otro lado, en la STS 482/2020, de 30 de septiembre, el TS se pronunció sobre el denominado caso Emarsa. A los efectos que en este apartado nos interesan, el gerente de una empresa pública (Entidad Pública de Saneamiento de Aguas Residuales, EPSAR) propuso al presidente el pago de costes en cantidades muy superiores a los que debían aprobarse para la gestión de la depuradora, algo que desconocía el presidente. Así, pese a que este último era quien dictaba y conocía el contenido de las resoluciones, desconocía el carácter injusto de las mismas. Como es sabido, el principio de accesoriedad limitada exige que el hecho del autor sea típico y antijurídico, razón por la que reiterada jurisprudencia del Tribunal Supremo ha establecido que la ausencia de conocimiento de la injusticia no excluye la tipicidad, sino la culpabilidad: una interpretación que resulta dogmáticamente cuestionable, pero que evita la impunidad del 
cooperador en casos como el que aquí se presenta. Así las cosas, la sentencia señala que el elemento «a sabiendas de su injusticia» no debe llevar a considerar atípica la actuación del funcionario en estos casos, sino únicamente a su exculpación cuando no actuó bajo dicha condición, y que los actos que dolosamente inducen o cooperan al firmado de la resolución injusta resultan penalmente ilícitos y deben ser, en consecuencia, castigados como tales.

\subsection{La necesidad de dolo directo}

La STS 57/2020, de 20 de febrero, reitera la doctrina jurisprudencial del Tribunal Supremo relativa a la necesidad de que concurra dolo directo para poder apreciar la prevaricación. En esta ocasión, el tesorero del Ayuntamiento de Tahá de Pitres (Granada) había firmado una serie de documentos que sirvieron para obtener financiación ilegal del ayuntamiento, tras un acuerdo entre la alcaldesa y el secretario interventor. La sentencia de instancia establecía claramente que el tesorero había actuado a título de dolo eventual, señalando que este se representó, antes de la firma de los documentos, un resultado que lesionaba el bien jurídico protegido, y que, con su firma, consecuentemente, el tesorero lo puso en peligro concreto, aceptando y conformándose con la producción de dicho resultado; un resultado que sabía que no podía controlar, pero que le resultaba absolutamente indiferente en cuanto a su producción, a pesar de representarse la misma, y pese a lo cual ejecutó la acción (la estampación de su firma). En consecuencia, la mencionada sentencia absolvió al tesorero, pues el delito de prevaricación no puede cometerse mediante dolo eventual, requiriendo dolo directo (al exigirse actuar a sabiendas de la injusticia de la resolución), con la finalidad de dictar una resolución arbitraria en un asunto administrativo. Por supuesto, tampoco cabe la imprudencia.

\subsection{Relaciones concursales}

La SAP Madrid-16 386/2020, de 16 de octubre, resuelve el caso de la interventora del Ayuntamiento de Serranillos del Valle (Madrid). En este caso, en virtud del Real Decreto-ley 4/2012, se había puesto en marcha en dicho ayuntamiento un mecanismo ágil de pago y cancelación de deudas con proveedores de entidades locales y de su financiación, y, utilizándolo, la interventora del ayuntamiento impulsó y autorizó la tramitación irregular de un crédito a favor de un particular que nunca había trabajado para este ayuntamiento. Así, generó la creencia de que existía una obligación pendiente de pago en dicho ayuntamiento a favor de dicho particular. Por estos hechos, la funcionaria fue condenada por un delito de prevaricación, un delito de falsedad en documento mercantil cometido por funcionario público y un delito de malversación de caudales públicos, todos ellos en concurso medial: en relación con la prevaricación, la interventora del ayuntamiento certificó la existencia de una deuda inexistente; en relación con la falsedad, por los documentos aportados para conseguir el abono de dicha deuda, que 
eran falsos; $y$, por último, señala la sentencia que ambos delitos fueron un medio para conseguir el fin que pretendían ambos sujetos: apropiarse de la factura indebidamente abonada.

\subsection{El delito de nombramientos ilegales}

La SJP Valencia-6, de 19 de febrero, condena al alcalde de Canet d'En Berenguer (Valencia) por un delito de nombramientos ilegales del art. 405 CP. En el caso que resuelve dicho pronunciamiento, este alcalde había nombrado a través de un decreto a su prima para ocupar una plaza de técnico de gestión de carácter interino. Dicho decreto era la única documentación que existía respecto al nombramiento de esta persona, no existiendo ningún tipo de expediente administrativo, informe previo o convocatoria pública alguna que garantizara el respeto a los principios constitucionales básicos de mérito y capacidad, igualdad y publicidad. Se trató, por tanto, del dictado de una resolución en la que se omitió todo trámite o procedimiento administrativo. Debe recordarse que el Tribunal Supremo ha establecido que el art. 405 CP, que establece una conducta prevaricadora concreta, solo debe aplicarse cuando la actividad se haya centrado en el acto concreto del nombramiento, mientras que, si, por el contrario, la conducta cubre un amplio proceso de la decisión, los hechos deben subsumirse en el delito de prevaricación recogido en el art. $404 \mathrm{CP}$ (por todas, STS 125/2016, de 22 de febrero).

\section{Desobediencia y denegación de auxilio}

La STS 477/2020, de 28 de septiembre, recoge, a propósito del caso Torra, la doctrina jurisprudencial sobre el tipo básico de desobediencia. Así, señala en primer lugar que el art. $410.1 \mathrm{CP}$, en cuanto a la acción, consiste en negarse abiertamente a dar el debido cumplimiento a determinadas órdenes judiciales o administrativas, configurándose como un tipo de mera actividad (o inactividad) que no comporta la producción de un resultado material: basta la omisión o pasividad propia de quien se niega a ejecutar una orden legítima dentro del marco competencial de su autor. Por ello se comprende dentro del tipo tanto la manifestación explícita y contundente contra la orden como la adopción de una actitud de reiterada y evidente pasividad a lo largo del tiempo sin dar cumplimiento a lo mandado, es decir, la de quien sin oponerse o negar la misma, tampoco realiza la mínima actividad exigible para su cumplimiento. Asimismo, cuando el sujeto, en vez de acatar el mandato, se limita a argumentar en contrario, «la réplica se convierte en una camuflada retórica al servicio del incumplimiento», señalando el Tribunal en este sentido que, de no ser así, se estaría reconociendo una singular forma de exclusión de la antijuridicidad en todos aquellos casos en los que la ejecución de lo resuelto sea sustituida, a voluntad del requerido, por un intercambio de argumentos con los que enmascarar la conducta desobediente. $\mathrm{Y}$ es que la concurrencia del delito de desobediencia, tal y como lo describe el art. 410.1 CP, depende de que el sujeto activo 
ejecute la acción típica, no de las afirmaciones que aquel haga acerca de su supuesta voluntad de incurrir o no en responsabilidad.

Señala, asimismo, la sentencia, que el delito de desobediencia cometido por autoridad o funcionario se integra de tres elementos: i) un presupuesto jurídico administrativo (la revisión, pronunciamiento o dictado de una sentencia o resolución procesal por un órgano judicial, o de una orden por autoridad o funcionario administrativo y que la sentencia, resolución u orden se haya dictado por órgano judicial o administrativo competente y con observancia de las normas procedimentales legales, y que la sentencia, resolución u orden conlleve una obligación de actuar de determinada forma o de no actuar, para ciertas autoridades o funcionarios, precisamente para que se logre la efectividad de la sentencia, resolución u orden); ii) que la autoridad o funcionario no desarrolle la actuación a que le obligue la sentencia u orden o despliegue la actividad que le prohíban tales resoluciones (equiparándose la abierta negativa a la pasividad reiterada y/o a la actuación insistentemente obstaculizadora), y iii) el elemento subjetivo, que requiere el conocimiento de la obligación de actuar generada por la resolución del tribunal o del superior administrativo y el propósito de incumplir, revelado ya por manifestaciones explícitas, o implícitamente por el reiterado actuar opuesto al acatamiento de la orden, sin que se admita la posibilidad de comisión culposa del delito de desobediencia.

\subsection{La relación entre los arts. 410 y $411 C P$}

El AJP Pamplona-4, de 6 de octubre de 2020, aborda el caso de la secretaria del Ayuntamiento de Fustiñana (Navarra), quien se negó, durante los años 2018 y 2019, a tramitar los expedientes de matrimonio civil presentados por los ciudadanos de Fustiñana, obligándoles a desplazarse hasta Tudela (pese a los requerimientos realizados por el personal del Registro Civil de Tudela para que cumpliera con su función). Si bien el Ministerio Fiscal formuló escrito de acusación contra la secretaria como autora de un delito de desobediencia del art. $411 \mathrm{CP}$, tras la celebración del juicio oral, las partes elevaron a definitivas sus conclusiones provisionales, pero el Fiscal, de forma subsidiaria, interesó la aplicación del art. 410.1 CP. Señala la resolución que dichos delitos son homogéneos y que, de hecho, el art. $411 \mathrm{CP}$ hace referencia en su tenor literal al art. $410 \mathrm{CP}$, que ha tenido un mayor desarrollo jurisprudencial (vid. supra). Cumpliéndose con los elementos del tipo del art. $410 \mathrm{CP}$, y siendo este más favorable que el art. $411 \mathrm{CP}$, el primero se acoge con preferencia.

\section{Tráfico de influencias}

Si bien el pronunciamiento que aquí se refiere se aleja del ámbito municipal, merece la pena reseñar la STS 693/2019, de 29 de abril de 2020, referida al caso Palau de la Música, en la que el Tribunal Supremo establece que cabe condenar por este delito pese 
a desconocerse los concretos actos de influencia y los funcionarios influenciados. Basta, por tanto, con que exista prueba suficiente de que la influencia se produjo y de que fue suficiente para introducir en la motivación del funcionario influenciado elementos ajenos a los intereses públicos, que deben ser los únicos ingredientes de su análisis, previo a la decisión.

\section{Fraude a la Administración}

La ya mencionada STS 696/2019, de 19 de mayo de 2020, relativa a la permuta de unos terrenos municipales para evitar una venta pública ideada y llevada a cabo por el entonces alcalde de Jerez de la Frontera y el gerente de la Gerencia Municipal de Urbanismo, también condena a ambos sujetos por un delito de fraude a la Administración del art. $436 \mathrm{CP}$. Tal y como señala la sentencia, este delito es un delito tendencial, de mera actividad, que no necesita para su consumación ni la producción de un efectivo perjuicio patrimonial ni el desarrollo ejecutivo del fraude, lo que no exime de la necesidad de concretar ese concierto, en su caso, entendido como concurrencia de voluntades, así como su potencialidad del plan trazado para producir el efecto perjudicial para el erario público. Asimismo, apunta que, de acuerdo con la jurisprudencia anterior, desde la perspectiva del elemento objetivo, para condenar por dicho delito basta con que exista un riesgo de que se ocasione un perjuicio económico para la Administración derivado de la forma ilegal en que se hace la adjudicación de un contrato sin pasar por el procedimiento de licitación pública. En cuanto al elemento subjetivo, este delito requiere que la adjudicación o contratación ilegal se haga con el propósito de defraudar a la Administración, de manera que, si este propósito no consta probado, sino que solo se prueba la intención de favorecer a una determinada persona o empresa mediante un sistema restringido de adjudicación sin buscar un perjuicio económico para el ente público, la conducta no resulta punible. En el caso concreto que aquí nos ocupa, el Tribunal estimó que no cabía duda alguna acerca del concierto de voluntades de los acusados con los responsables de la empresa propietaria del inmueble objeto de la permuta, apuntando que concurría tanto el elemento objetivo (pues tuvo que existir una negociación entre ambas partes que resultaba en un perjuicio para los intereses municipales y posibles terceros interesados), como el elemento subjetivo, pues tanto el alcalde como el gerente conocían que no existía necesidad alguna que justificara la permuta.

Por otro lado, en relación con el perjuicio, debe mencionarse el ya referido ATS de 6 de octubre, en el que se dirimía el caso del alcalde de Girona, quien había adquirido para el Museo Municipal una colección de obras de arte habiendo abonado parte del precio (1.000.000 de euros) con el importe recibido por el ayuntamiento en una operación de prórroga de concesión para gestionar el cobro del canon del agua, y cuyo destino debía haber sido la financiación del gasto municipal relacionado con el ciclo integral del agua. En esta ocasión, el Tribunal Supremo sostuvo que no podía considerarse perjuicio en 
el patrimonio del ayuntamiento el hecho de que dejara de invertirse una determinada cantidad en la red de saneamiento y agua potable, y que el cambio de las partidas presupuestarias había sido aprobado por el Pleno del Ayuntamiento con conocimiento de su origen y destino. Así, estableció que, sin perjuicio de que la operación realizada por el alcalde hubiera sido ilegal, no había existido artificio alguno para defraudar al ayuntamiento.

\section{BIBLIOGRAFÍA}

Con carácter general sobre estos delitos, merece la pena destacar, en primer lugar, la actualización del Memento Práctico Penal 2021, en Molina Fernández (coord.), Francis Lefebvre, 2020.

Por otro lado, sobre el fenómeno global de la corrupción son varias las contribuciones publicadas durante el año 2020, entre las que pueden señalarse «Actividades urbanísticas delictivas, crisis económica y corrupción: responsabilidad de las personas jurídicas» (ACAle SÁnCHEZ, Revista General de Derecho Penal, núm. 34), o "Corrupción en el sector público" [NAVARRO CARDOSO, Una década de reformas penales: análisis de diez años de cambios en el Código Penal (2010-2020), en Bustos Rubio y Abadías SelMA (dirs.)—, J. M. Bosch Editor]. También con carácter general a los delitos contra la Administración pública se ha publicado «El concepto de funcionario público a efectos penales: una revisión del sujeto activo funcionario en los delitos de cohecho» (DELGADO GiL, La Ley Penal, núm. 145).

Asimismo, durante el año pasado, también se han publicado contribuciones específicas a los delitos que conforman el Título XIX del Libro II, entre las que pueden señalarse "Regulación penal del tráfico de influencias" [DÍAZ-MAROTO y VILLAREjO, en Transparencia, lobbies y protección de datos - BERMúdeZ SÁNCHEZ y DE MARCOS FERNÁNDEZ (coords.) —, Aranzadi Thomson Reuters]; «Consideraciones sobre algunos problemas específicos de autoría y participación en los delitos de cohecho» [GARCía ARROYO, en Derecho penal y politica criminal en tiempos convulsos: Libro homenaje a la Prof. Dra. María Isabel Martínez González -Galán Muñoz y Mendoza Calderón (coords.) —, Tirant lo Blanch]; «Reflexiones sobre urbanismo, ordenación del territorio y prevaricación: luces y sombras de una reforma» [RODRíGUEZ ALMIRÓN, en Una década de reformas penales: análisis de diez años de cambios en el Código Penal (2010-2020) —Bustos Rubio y Abadías Selma (dirs.)—, J. M. Bosch Editor].

Por último, si bien no se trata de un volumen sobre delitos contra la Administración pública, en el Libro Homenaje al Profesor Diego-Manuel Luzón Peña (Reus, 2020) se encuentran varios artículos relacionados con aspectos específicos de los delitos contra la Administración pública, entre ellos: «Política criminal en la prevención de la corrupción y delitos económicos transnacionales» (BACIGALUPO SAGGESE); «La respuesta penal frente a la corrupción internacional: algunas reflexiones político-criminales» (BERDUGO 
GÓMEZ DE LA TORRE); «Tráfico de influencias artículo $430 \mathrm{CP}$ : ¿es necesario que el sujeto que ofrece influencias realmente las posea o es suficiente con la voluntad de conseguirlas?» (ÁLVAREZ ÁLVAREZ); o «La inconsistente inclusión del delito de malversación de caudales públicos en el modelo de responsabilidad penal de las personas jurídicas, a través de la reforma del Código penal operada por la Ley Orgánica 1/2019, de 20 de febrero» (FERNÁNDEZ TERUELO). 